\title{
Urban Design of Old Town from the Perspective of Context Continuation
}

\author{
Xiaoxiao Zhang ${ }^{1,2}$, Jianxiong Yan $^{3}$, Renyi Liu ${ }^{1,2}$ \\ ${ }^{1}$ College of Architecture and Urban Planning, Anhui Jianzhu University, Hefei 230022, China \\ ${ }^{2}$ Key laboratory of Huizhou Architecture in Anhui Province, Hefei 230022, China \\ ${ }^{3}$ Anhui Provincial Architectural Design and Research Institute Co., Ltd., Hefei 230601, China
}

\begin{abstract}
The current urban development in China has generally entered the stage of urban renewal. Facing the urban mix of old and new, different forms of collage picture, the urban design exploration of continuing the urban context has important theoretical value and practical significance for the urban renewal of the old urban area. Based on the analysis of the explicit and implicit context, this paper raises six strategies for urban design in the old city, namely texture improvement, building integration, interface reconstruction, information implantation, functional compounding, and benefit balancing. As an empirical evidence, the urban design of the old city further discusses the importance of the continuity of the context for urban renewal in the old city.
\end{abstract}

\section{Introduction}

At present, "juxtaposition" is the typical scene in the old urban area: traditional historical streets, towering skyscrapers, dilapidated shanty towns and modern upscale residential areas. The mixture of the old and the new, and the different elements of the form all appear surprisingly on the same canvas. Facing the "juxtaposed" collage picture, it is of great theoretical value and practical significance to explore the continuity of context in the spatial order, urban image and development guidance of the old urban area by means of urban design, so as to retain the nostalgic memory of local residents.

\section{The meaning and composition of context continuation}

\subsection{Meaning of Context Continuation}

In their works, Revitalizing Historic Urban, Quarters, Steven Tiesdell, Tim Heath, Taner Oc sum up and put forward three development modes of historic district: contextual unification, contextual juxtapose and contextual continuance.$^{[1]}$ The integration of context refers to imitating and copying the architectural features of historical blocks. The juxtaposition of context refers to the separation from the past and the insertion of new modern buildings into the historical block. The combination and juxtaposition of context will to some extent destroy the original texture of context. While context continuation is a widely recognized development idea besides over juxtaposition so that context cannot continue and blind imitation so as to solidify context, which is a new interpretation of the relationship between the old and the new. The city is an entirety of historical accumulation in various periods, which often presents the form of "collage". Context continuation is a cognitive method of "collage" and an effective means of urban renewal.

\subsection{Composition of Context Continuity}

As early as 1951, Clyde Crookhoun, a famous American anthropologist, divided the types of context into explicit context (materialized cultural facts) and implicit context (values with cultural connotations). ${ }^{[2]}$ As shown in Figure 1 , the composition of urban context includes the dominant and recessive elements. The dominant elements refer to the perceptible and tangible carriers of spatial form in the city, including the natural environment and built environment. Natural environment includes topography, river system, etc., which are the decisive factors of the overall urban form and regional culture. The built environment includes urban pattern, urban texture, architectural form, and public space. Recessive elements refer to the spiritual inner and intangible cultural ideology, including social culture and human psychological behavior. Social culture includes historical culture, economic form, social organization, traditional folk custom, religious belief, etc. While human psychological behavior includes collective memory, aesthetic style, lifestyle, etc.

The composition of the continuation of the explicit context can be divided into three aspects, which are urban texture, architectural form and interface composition. Urban texture contains history and forms a new urban context through the combination of traditional texture and new 
development elements. Urban texture develops urban culture in the long process of evolution and historical accumulation. The traditional characteristics of urban texture make it the carrier of specific culture, as the "DNA" of urban development. Architecture is an artificial material space, an important place for production and life, and a direct expression of cultural characteristics. Aldo Rossi, a famous architect, believes that summarizing and abstracting the historical prototype, combining with other architectural elements to design and transform, and then creating a building with both historical characteristics and specific needs will continue its cultural characteristics. ${ }^{[3]}$ Therefore, the architectural form in the existing environment should be summarized in an abstract way. The new building should be " endowing the old with the new, and grasping the ideas and forgetting the emblems". Streets and squares, which are composed of the external interface of various architectural spaces, are

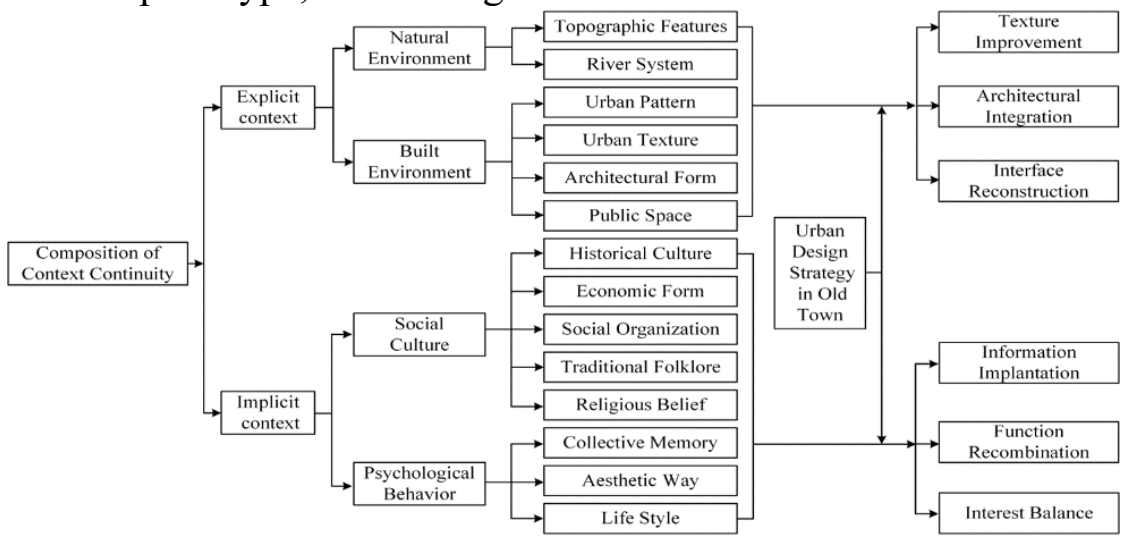

Fig. 1. Constitution of Context Continuation

often the most memorable elements of a city. There are different types of external interfaces including but not limited to roof, facade, side elevation, ground, and enclosure.

The composition of the continuity of the implicit context can be divided into three aspects: historical information, function needs and interest coordination. Various historical legacies are left in the process of urban change, such as the historical names of people, streets, buildings and cities. They are the carrier of history, geography, and culture, and a significant support for the continuation of urban context. New urban functions and residents' needs are also a reflection of urban implicit context. Different functions need different architectural forms. The old urban area should pay attention to the diversity of functions and social life, integrate and select the implicit context, reasonably put in new functions, and then guarantee the continuity of the context. The renewal of the old urban area involves complex social and economic relationships. There are two types of stakeholders: main stakeholders including government, developers and the public, and executive stakeholders such as designers. The participation of multiple stakeholders in the process of urban design is a kind of human psychological behavior (a kind of implicit context). The coordination of interest relationship is the key process to realize the continuity of context, and also one of the main principles to judge urban design.

\section{Urban Design Strategies of the Old Town}

For urban design, context continuation is maintaining the continuity of original space, culture and life and highlights the urban characteristics through the analysis and research of urban context in specific block design. Based on the analysis of the composition of context continuation mentioned above, the paper summarizes the experience of urban design, which is continuously improved, and sums up the following points.

\subsection{Improving urban texture}

The main problem of the old city is congestion and narrow roads. In the process of old city renewal, it is bound to widen the narrow motorway, connect the Cul-De-Sac, increase the access road density, and improve the traffic problems in the old city. The road design should follow the original road texture, and make sure that the road is curved without blocking, accessible without winding. The widening of motor vehicle roads should be moderate, the width of the red line should be controlled within 12 metres, and one-way roads can be adopted. Pay attention to the density of pedestrian road network, encourage the open design of residential areas, and form the texture pattern of "small blocks with dense road network".

\subsection{Building Integration}

The buildings in the old city should be organically 
integrated with the old and the new to be laden with history. On the basis of the original historical building, the new building that continues the context should abstract the interpretation method combining with the modern context, achieve "seeking common points while reserving differences", and show the traditional fusion and dynamic growth of the existing buildings. Scale controlling is particularly important. High and large buildings should be treated as comfortable small-scale units by means of decomposition and sinking, so as to maintain the traditional space atmosphere.

\subsection{Interface Reconstruction}

There are two ways to deal with interface reconstruction: isomerism and heterogeneous isomorphism. The symbolic elements of historical buildings should be abstracted, deformed and applied in the interface. The interface design should be both unified and different through the ingenious changes of structure, material and colour. The application of glass makes the interface more transparent and modern, reducing the heaviness and closeness of the building. The local bright color can increase the commercial atmosphere and space identification of the block. The use of modern building structure, materials and colors makes the interface more free and diverse.

\subsection{Information Implantation}

In addition to the preserved historical buildings, traditional streets and lanes, and ancient trees, new buildings, roads and squares will also be added to the old town, which can be given relevant historical names and recall people's memories. For landscape design, reliefs and walls can also be used to display historical information such as biographies, stories and legends of celebrities. Embedding historical information into urban renewal fine design plays an important role in the continuation of implicit context.

\subsection{Functional Composite}

The old town is a unique public activity space and a highquality leisure experience place in which citizens can fully experience the city's history, charm and vitality. The traditional street pattern and architectural form determine the suitable functions, such as characteristic catering, cultural creativity, boutique accommodation, leisure, and entertainment. Urban cultural facilities are the first choice of functional business in the old urban area, museums and gallery can be put either by transforming from old buildings or by newly built. The function combination based on business culture not only makes people and the environment coordinate, but also integrate the old and the new.

\subsection{Interest Balance}

Integrating and balancing interests is a dynamic and complex process. Urban design aiming at actual landing and guiding construction must reach the final balance of interests. The main contradiction of the renewal of the old town lies in the reduction of the development intensity of the land and the increase of the pressure of the investors on the return of funds to maintain the traditional spatial pattern. In the balancing process of the profits and context continuation, the key is to keep the appropriate traditional space scale. public interest of the society and the long-term development of the city should be put in the first place, the balance point can be achieved through the comparative demonstration of multiple schemes. Promoting the government's urban renewal work and meeting the economic returns of investors will make residents enjoy high-quality living environment.

\section{Urban Design Case of Old Urban Area in Wuhu County}

\subsection{Project Overview and Positioning}

The total area of the project is about $3.92 \mathrm{~km}^{2}$. Wuhu County was called Jiuzi in ancient times, and later moved to Wanzhi Town, with Qingyi River in the West. It is an important commercial port in southern Anhui. In 1930s, it was called "little Shanghai". At present, the old town still maintains the texture pattern of "nine neighbourhoods and eighteen lanes" in the prosperous period of Wuhu County, which integrates the advantages of historical context, Zhijin culture and the picturesque river. The case will take the image orientation of "the hometown Wanzhi" to let the residents feel the traditional street pattern, the historical building style, the interesting life sentiment and the rich nostalgic memory, letting the old town become the "hometown 'Wanzhi' which remains nostalgia" and the new symbol which represents Wuhu County.

With the continuous improvement of the environmental quality of the old town, it will become the key area of Wuhu County. It is expected as a high-quality and liveable demonstration area with beautiful environment, comfort and convenience lifestyle, and complete supporting facilities, an urban garden focusing on riverfront tourism, leisure and sightseeing, and ecological experience, and the hometown of Wanzhi with a long history, rich culture, prosperous business and nostalgia.

\subsection{Continuation of Explicit Context}

1) Urban Texture of "Nine Neighbourhoods and Eighteen Lanes"

The old town of Wuhu is adjacent to Qingyi River in the West. Due to the rise of river transport, Wanzhi Street (He Yan Road) was the economic and trade center of the county at that time, with a length of about 1000 metres from south to north. Nowadays, the overall road pattern still exists. The old street is divided into upper Street (grain station department store, drugstore) and lower Street (old department store to blockhouse pond), leaving traces of the old "Bao-Jia system". As shown in Figure 2, Nine neighbourhood: the first one is the old department store area, the second one is the lotus pond area, the third 
one is Houwang temple in Shizi mountain (grain and oil factory) area, the fourth one is Tongyu sauce house area, the fifth one is the Wulao housing management association area, the sixth one is the bamboo industry (He Yan) area, the seventh one is the earliest male bathhouse area, the eighth one is from the old police station to the old department store and the old drugstore area, and the ninth one (because it is basically located in the lower street, also known as lower nine neighborhood) is from the old police station to blockhouse pond area. Eighteen lanes: lanes connecting the mountains in the East (the streets formed after the development and construction): Badou lane, Chejia lane, Xiaopenglai lane and some nameless alleys; alleys connecting the West Wharf He Yan Road (Qingyi River side): Houwang temple lane, Yitong lane, Theater lane, Heyan lane, Kuzidang lane, Badou lane, Bamboo lane, Caishi lane, Kudang lane, Yijiang lane, Shiqiangge lane, Xinheng Lane, Jiuqu lane, Chejia lane.

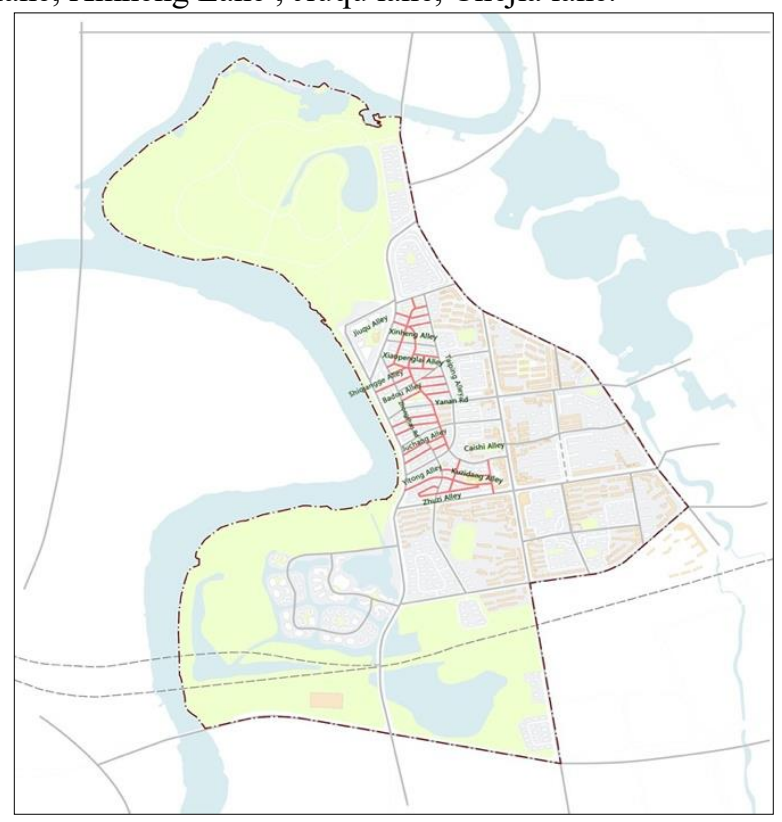

Fig. 2. "nine neighbourhood eighteen lanes"

The old town presents a unique urban texture pattern, which has become an important structural element of this urban design. On this basis, combined with the renewal strategy of texture improvement, the traffic capacity of the old urban area has been greatly improved. The pedestrian traffic links among the riverside view scenic area, the commercial and cultural area and the residential area are effectively organized to form a diversified and integrated pedestrian space system through opening the block and the river view platform across the riverside road

2) Style of Traditional Shops

The traditional buildings in Wuhu County still remain the characteristics of Huizhou architecture. They are low buildings and deep alleys. Most of the houses are made of brick and wood, with black bricks, black tiles and white walls, hard top Ma Tau Wall, and low lofts made of wooden boards. They are basically built in the late Qing Dynasty and the early Republic of China, remaining the style of Ming and Qing Dynasties. The shops along the street with eaves continued the ancient style of shops in front of shops and back houses, which was basically built in the late Qing Dynasty and the early Republic of China, leaving the style of Ming and Qing Dynasties. Shops along the street, with eaves at opposite angles, have retained the ancient shop style of the front shop and the back house. The back of the shop is the residence, courtyard and kitchen, which is the daily living place. Trees and flowers are planted in the courtyard, and the thatched shed (i.e. toilet) is built inside as shown in Figure 3.

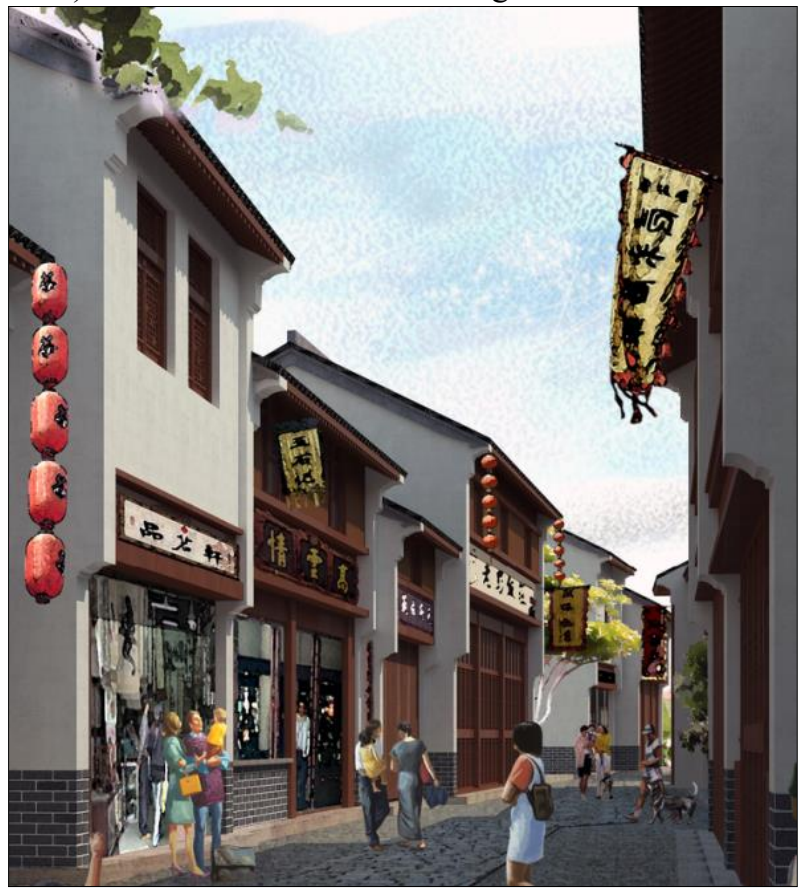

Fig. 3. Traditional Shop Architecture

The traditional retail buildings in Wuhu County have their own characteristics of spatial layout and details, which will become an important spatial element of this urban design. In addition to a few historical buildings retained, all other buildings have been demolished. In the core controlling area with continuous context, new buildings integrate with historical buildings in terms of height, colour and style. In the scene coordination area of continuous context, the new buildings adopt the symbol element of traditional building and is related to historical building in terms of style and feature, forming an organic and unified overall spatial image.

3) Remembering the Image of Wanzhi's Homesick Hometown

The main public activity space in the old town is alongside the Qingyi River, including Zhijin Cultural Square, air corridor, Qingyi Riverbank, observation tower, etc. The riverside interface is the key content to display the image of the old city. First of all, the building height and style in the riverside area should be controlled. Building height should lower than three floors, and the style is mainly modern Huizhou architecture. The facade of the building and the gable should be interspersed with each other, false and real complemented, and high and low scattered. Secondly, an observation tower should be built to become the commanding point of the interface alongside the river, overlooking the city and enjoying the scenery.

The old town is divided into two areas and four 
interfaces from west to East. The core control area includes the riverside business area interface and courtyard residential area interface, and the scene coordination area includes multi-storey, small high-rise residential area interface and high-rise residential area interface. As shown in Figure 4, The overall space is rich, diverse and orderly, forming a unique urban space style of the old city.

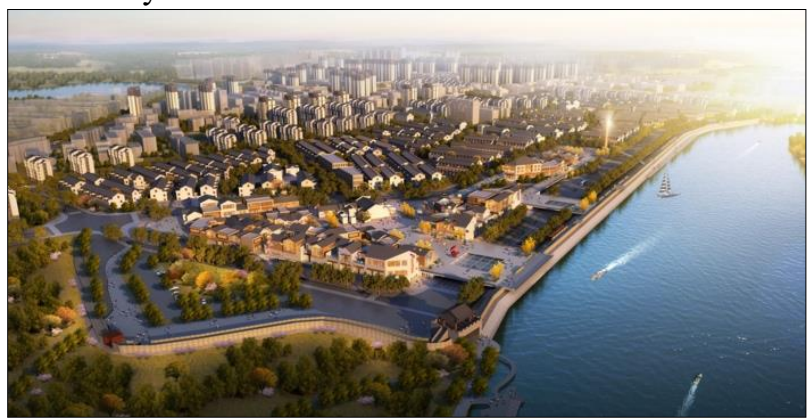

Fig. 4. Remembering the image of Wanzhi's homesick hometown

\subsection{Continuation of Implicit Context}

\section{1) Organic Integration of Historical Information}

Except for the historical information of "nine neighborhood eighteen lanes", the original Catholic Church and Guanwangdu wharf were repaired to maintain the original historical buildings. The preserved historical buildings were transformed into celebrities' museums and Mie's museums, showing the historical photographs and collections of allusions in Wuhu County for people to enjoy and review. In the historical business center of Wanzhi Town, a new culture square was built to show and inherit the unique culture of Wuhu County.

In addition, we can regularly organize and carry out the "intangible cultural heritage" activities in Wuhu County, such as plating dragon lantern, temple fair, handicraft, etc., so as to organically combine historical information with historical space environment.

\section{2) Strengthen Cultural and Leisure Functions}

According to the requirements of the overall planning of Wuhu County, the old urban area mainly has the functions of commerce and residence, but the function of culture and leisure is relatively lacking. Therefore, the function of the preserved building will be replaced by the cultural function, and a new cultural square will be built. Due to the blocking of the flood control wall in the west of Qingyi River, there is a lack of interaction between the river and the town, which has a great impact on the leisure and recreation of the old urban area. Therefore, the second floor of the riverside building is connected with each other through the viewing platform to form a continuous walking air corridor. The main entrance of the platform is set up in Zhijin Cultural Square, and the observation tower is used as a sign of entrance sight. The old town is connected with the key functional areas such as Wufengtan Park, Qingyij River, Donghu Park, Yan An Road pedestrian block, and the leisure space of the whole area is connected. As shown in Figure 5.

Open and diversified modern urban functions and traditional historical and cultural functions supplement each other, which is a relatively accepetable way of urban context continuation at the present.

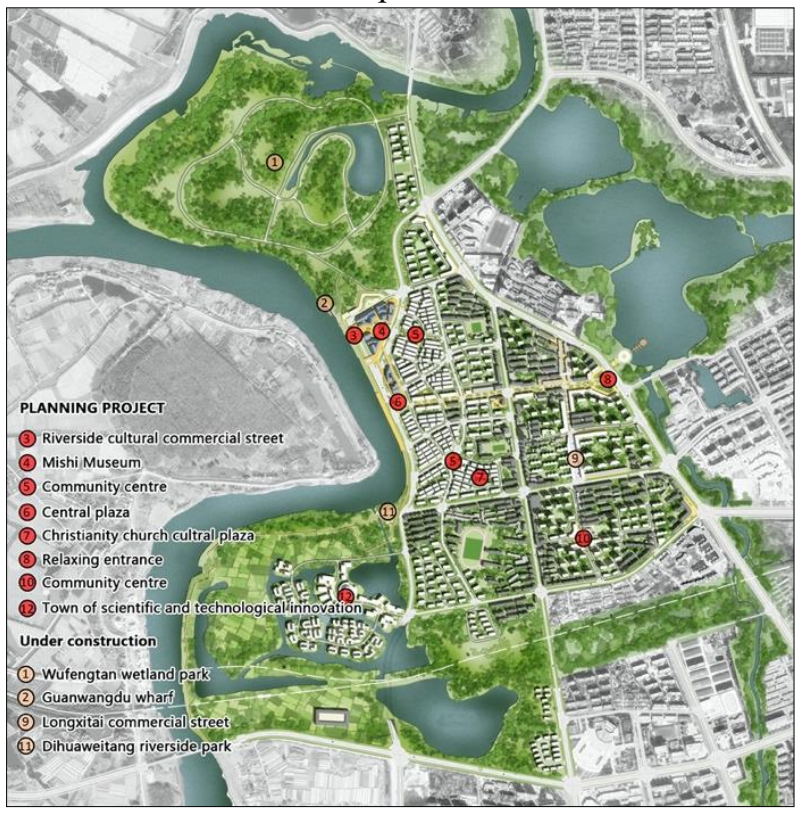

Fig. 5. General plan of urban design

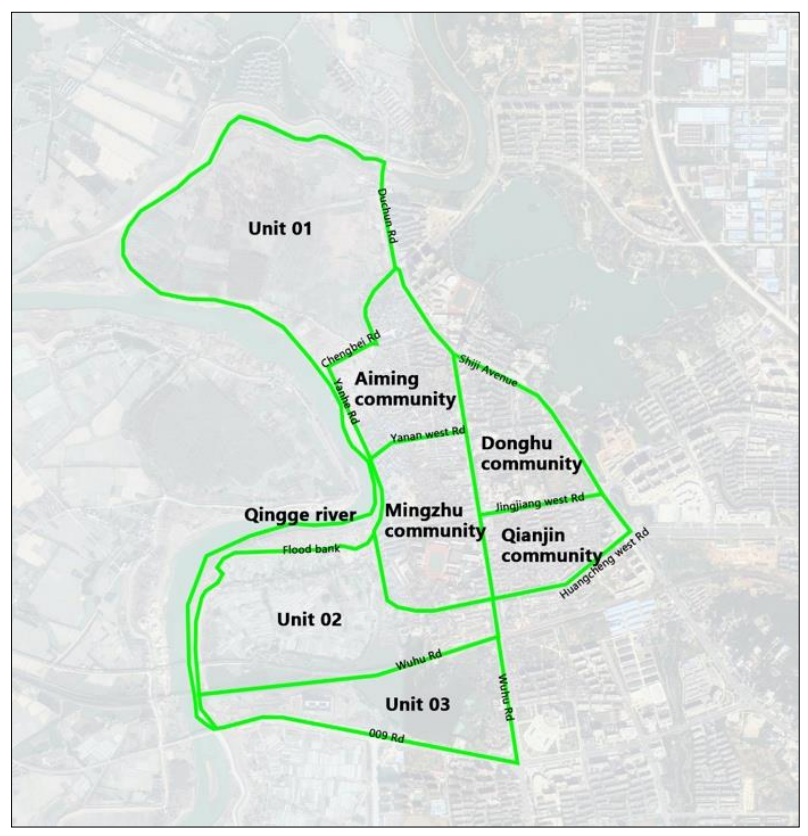

Fig. 6. Renewal Management Unit Diagram

3) Unit Control, Complementary Indicators

According to the requirements of Wuhu County Government, the minimum development intensity of this area is 1.6. According to the relevant economic arguementation, the development of courtyard-style traditional buildings (which are lower than three floors) is the main one, and the maximum development intensity of land can reach 1.4. In order to achieve the dynamic balance of the economy and progressively promote the renewal and transformation of the old town, the old urban area is divided into seven renewal and transformation management units as shown in Figure 6. Each plot in the unit can be evaluated from multiple dimensions, and 
specific renewal and transformation contents can be formulated, such as transformation function, development intensity, development subject, fund operation, style guidance, etc. the difference and complementarity of land blocks can be solved effectively through the division, classification, and "one policy for one area" management method.

Among the 7 management units, the development intensity of the people loving community and the democratic community is controlled below 1.4, which is the core control area for the continuity of the context in the old urban area. The development intensity of unit 01 , unit 02 and unit 03 is controlled below 1.8, which is the scene coordination area for the continuity of the old urban context. The development intensity of Donghu community and Qianjin community is controlled below 2.0, which is also the style coordination area for the continuity of the old urban context. The average development intensity of the old urban area is controlled at about 1.76, which can realize the balance of renewal cost and benefit.

\section{Conclusion}

At present, urban development in China has generally entered the stage of urban renewal. The old urban area bears a precious historical context of a city. The urban design with the core of urban context plays an important role in the overall control of the renewal of the old city. Through six strategies of texture improvement: architectural integration, interface reconstruction, information implantation, function recombination and interest balancing. The urban design of the old town in Wuhu county has effectively integrated the city's explicit and implicit context, so that the vitality regeneration and cultural continuity of the old city will be integrated and developed. The urban design that extends the urban context not only solves the specific problems and contradictions of the city, but also progressively promotes the renovation and renovation of the city, and it is also an important method to build a better human settlement environment and achieve sustainable development. ${ }^{[4]}$

\section{Acknowledgement}

This paper is funded by the following projects:

1. Research on the Features of Anqing Modern Architecture (SK2018A0576)

2. characteristic of school and bilingual course construction project (2017ts05)

3. Specialty education and practice of civil engineering under the subject assessment background: Huizhou architectural culture characteristic education as an example (2017jyxm1192)

\section{Reference}

1. T. Heath, T. Oc, S. Tiesdell, R, Revitalising historic urban quarters, (2013)

2. C. Kluckhohn, R. Kluckhohn, FPNY, Culture and behaviour, (1954)
3. A. Rossi, P. Eisenman, MITC, The architecture of the city, (1982)

4. L. Zhang, L. Cheng, P, Urban Space Construction in The Cultural View: A Foshan Case, 31, (2014).

5. Wuhu Old Town Urban Design, APADRI, (2018) 